\title{
Koya city urban heritage conservation: challenges and potentials
}

\author{
S. B. Al Qaisi \\ Department of Architectural Engineering, Koya University, \\ Kurdistan Region, Iraq
}

\begin{abstract}
Walking through the winding roads of the old city of Koya can easily reveal some different historic layers as it is believed that people started living nearby from 2500 BC. Although there are several buildings and monuments that could be considered as good evidence of their eras in that city, unfortunately, their physical condition is getting worse through time due to bad maintenance and uncontrolled urban growth. This problem highlights the importance of studying carefully the challenges that face the urban growth of the city and affect negatively on its heritage. In order to find good solutions that could revive this heritage and make it a vital point to attract and enhance tourism, this paper starts with a historic review that shows the main morphological stages for the city, and states the importance of its heritage. It then refers to the main challenges that face this heritage, and discusses potentials that could protect and enhance the role of Koya's heritage in attracting tourism. The paper ends with recommendations that could draw a better future aspect for this important but yet unrevealed city.

Keywords: urban morphology, conservation, heritage, old city, Koya, Kurdistan.
\end{abstract}

\section{Introduction}

Koya is an ancient city; the urban life can be dated back to at least 2500 BC [1], its population is about 100,000 [2] the area of Koya district that belongs to Erbil is about $2050 \mathrm{Km}^{2}$. Koya is $620 \mathrm{~m}$ above sea level. It is located in the North East of Iraq and in the South East of the large Kurdistan between the two lofty mountains Bawaji (1260m height) and Haibat-Sultan (1092m height), [1] which can be considered as a touristic area. 


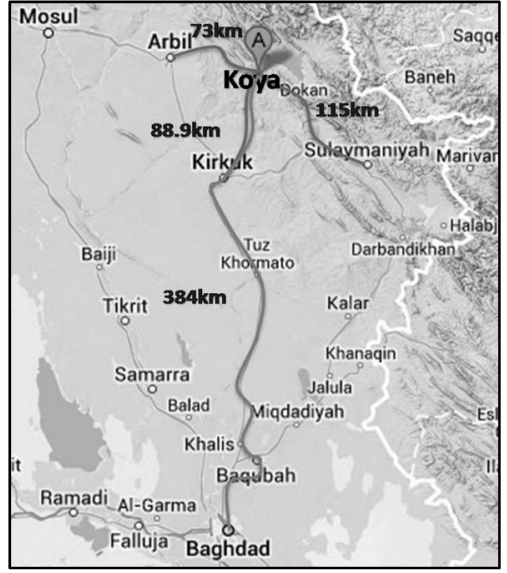

Figure 1: Koya's location [7].

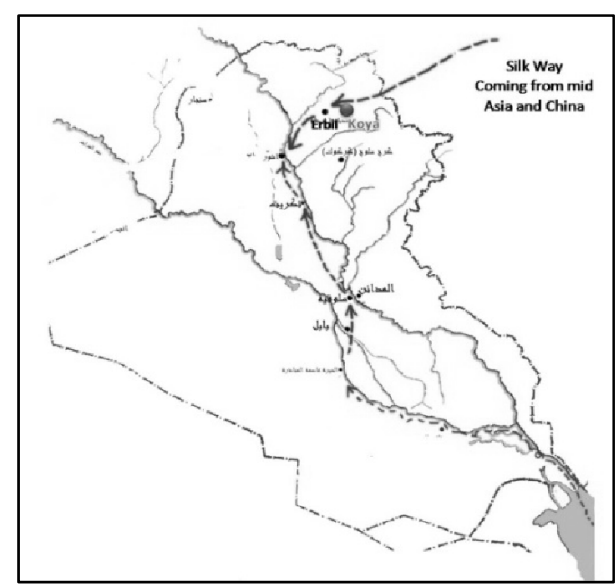

Figure 2: Koya's location within the Silk Way [8].

Fig. 1 shows the strategic location of Koya among three of the most important metropolises in Kurdistan Region (Erbil, Suleimany, and Kirkuk). Generally, it is considered as an agricultural area. The British provincial administrator and inspector Wallace Lyon travelled through the town in 1923 and noted that it was a centre for tobacco [2]. In 1918, it became a District; but within the former regime era it suffered a critical political situation as other Kurds' cities, it was, therefore, returned back to be no more than a small area within the countryside of Erbil in 1988; but when the Kurds' Revolution succeeded in 1991; KRG (Kurdistan Regional Government) turned it back into a district. Koya as a district has about 80 archeological sites [1]. It was famous with Arts, Music and Poetry; and has been known as a religious, scientific, literary and educational centre as it was the town of Haji Qadir Koyee (1817-1897), Malai Gawra (1876-1943) and Dldar (1918-1948) who were the three famous poets and social reformers who encouraged people to adopt science and realities of modern society to liberate and build an independent Kurdistan [2]. Lately it is famed for being the birth city of Mr. Jalal Talabani the current president of Iraq.

\section{Koya city: morphology}

The lack of information and accurate urban studies about this city puts a big responsibility on our shoulders as architects and urban planners and designers to cover this issue as much as possible; and because of the absence of clear morphological studies that show the initial formation of this city since its existing; this paper shows Author's analysis with a brief revision to the main morphological stages of the city as recorded in some historic and geographic Kurdish studies that help building a hypothetical image of Koya's urban transformations through time; as an access to further and more accurate studies. 
Exploring the map indicates that Koya was located within the (Silk Road), fig. 2, and that indicates that one of the main purposes of initiating it was probably to be a station for merchants; even during later epochs as within the Ottomans reign (16th-20th century) there are some evidences that the commercial purpose was the main one in this city, the Khans, and other places for merchants to have rest in this city; and being such a good land for agriculture support that purpose and ease settling in. Since most of the old existing buildings in Koya date back to the Ottoman era, and because of the lack of information and maps, this paper will detect the trace of this city urban form starting from the 19th century.

Koya old city consists of four main neighborhoods (Baizagha, Hewaw, Qalat, and Bafra-Qendi) [3]; it is believed that Baizagha, and then Hewaw had formed the initial nucleate of this city, the date of erecting them is unknown yet but they both existed before erecting the Qishla Citadel (Qalat) (which was built in 18691872 [4]) and then it started growing towards Erbil with Bafra-Qendi; the city then was with a semi-circular shape.

Within Ottomans' reign, the first city wall was erected and surrounded those four neighborhoods with a $1 \mathrm{~m}$ thickness in most of its parts; it was made of lime and stone [3]. With this kind of fortification, Koya had had its first clear urban form as a city; and added a new purpose which is a defensible purpose, this could be easily figured out by knowing that Koya had many Citadels, Qishla is just one of them and the biggest one. All the streets and paths were winding; and most of them had dead ends; the commercial land use was focused in the center of the city where all kinds of shops with two Qaissarias (which were built in 1840, and 1904 [5]) near the Great Mosque; the industrial land use could be figured out by the light industries and handcraftsmanship. That was the 1st morphological stage which lasted since its first existence until the mid of the 20th century [3] (fig. 3).

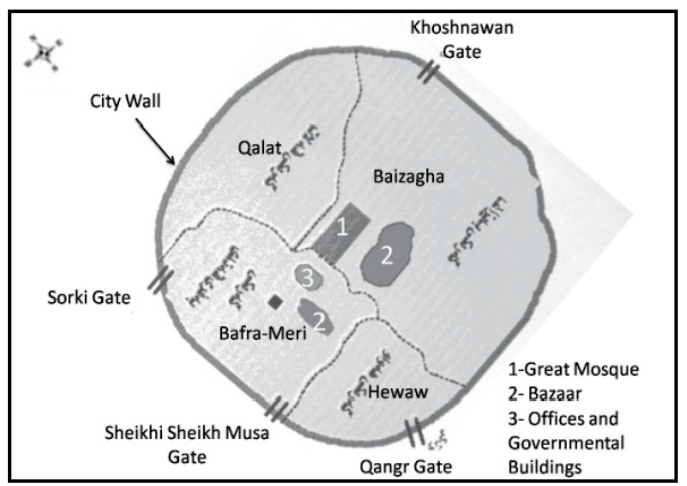

Figure 3: $\quad$ Koya during Ottoman’s reign (mid 19th century) [3]. 
Between 1952 and 1956 new streets and main crossroads were made such as Haji Qadir main street which was the first wide street; and the main street that linked Koya and Rania, such streets encouraged trade, therefore, the commercial land use expanded along those streets. That was the 2nd morphological stage [3] (fig. 4).

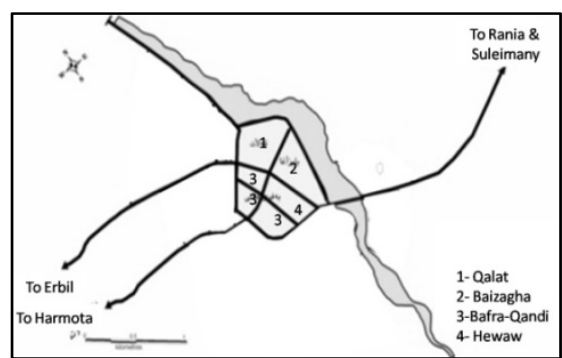

Figure 4: Koya city in 1950s [9].

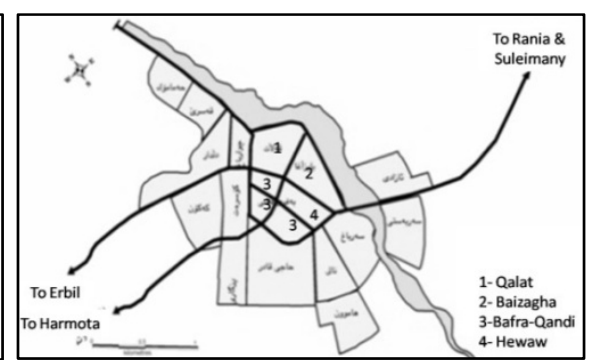

Figure 5: Koya city in 1992 [10].

The 3rd stage dated from 1961 to 1979, as the main strait streets encouraged adopting a grid iron type of planning for new sectors. Since 1980's the city suffered an uncontrolled demographic increasing due to the migration from rural parts to the city center, and a critical political situation. That disturbance led people to possess lands illegally and build their houses in, as in Kakon, and Azadi neighborhoods where people suffered poverty and bad infrastructure. This was the 4th stage [6]. After growing with a central shape and organic type of paths network; the city started growing radiantly towards Erbil, Suleimany, and Rania, taking the shape of the main streets, and with a grid iron type of paths network around the old urban nucleate (figs 5 and 6). In 2003 the city grew towards Rania with a new urban nucleate that had been established with erecting Koya University and draw the urban growth towards it (fig. 6); that was the 5th stage.

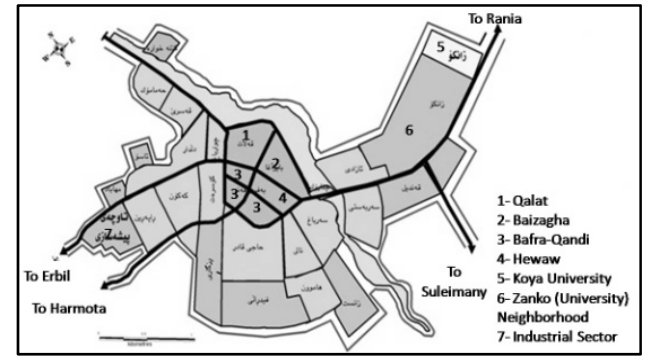

Figure 6: $\quad$ Koya city in 2007 [10]. 
Fig. 7 shows that the old urban nucleate is a (commercial-religiousresidential) sector; while the new urban nucleate is an (educational-residential) sector; which is in the eastern edge of the city (fig. 8), declaring that the future expected expansion would probably try to enclose it and make a new kind of edges which would be (commercial-residential-entertainment); while city's western edge is of an industrial use; that regarding to the new projects could be of a residential use.

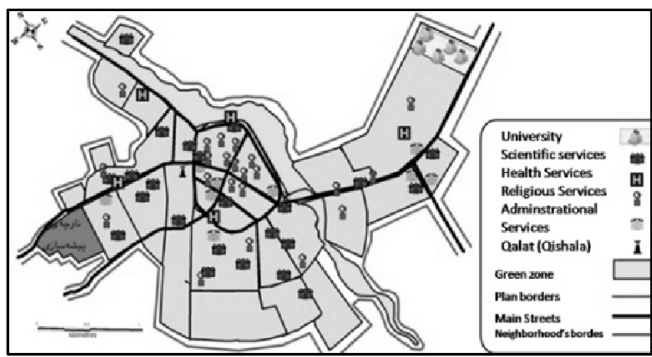

Figure 7: Koya city in 2007 - main services that indicate land use layout [10].

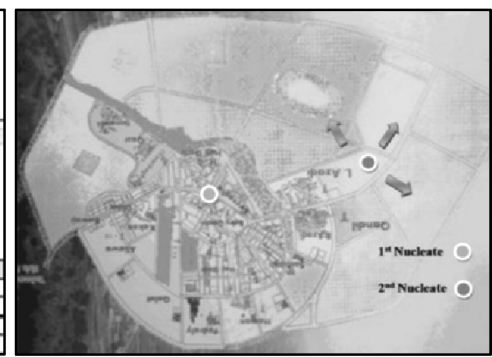

Figure 8: $\quad$ Koya city in 2007 - the expansion around Koya University [6].

\section{Koya city: heritage}

Koya's old city still keep some good evidences from its 1st and 2nd morphological stages which could form its urban heritage enhanced by the old urban fabric which still intact in some places. Many sources had mentioned several of those evidences such as Qishla, Khani Gawra, Qaissariyas, old houses from different epochs, and other buildings/features from the Ottomans reign on. The recent physical condition for those important buildings and features is so bad, even after being maintained (figs 9 and 10). This heritage is still neglected, and can't attract tourism with its current situation and could be a victim of demolition in any time.

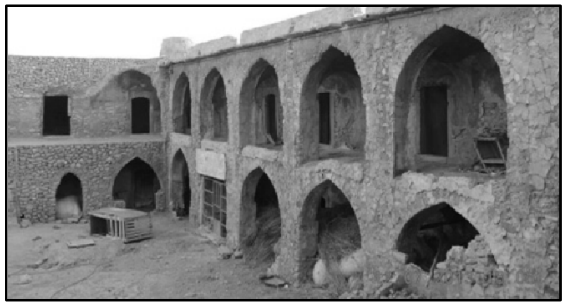

Figure 9: The neglected Khani Gawra [11].

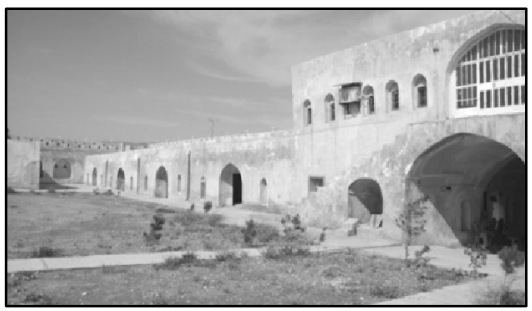

Figure 10: Qishla after maintenance [12]. 


\subsection{Challenges}

Reviewing Koya's morphological stages, streets, and heritage physical condition indicate many challenges that face city's heritage; here are some of them:

- The lack of documentation, maps, and accurate urban studies for the city, due to that, the maintenance for the individual historic/cultural buildings and features most probably goes wrong.

- Neglecting the old buildings especially those which have a historic/cultural value; they are either damaged or partially destroyed and full of dirt.

- Having a new urban nucleate in the city was one of the reasons of neglecting the old one as there's no connection between the 1st and 2nd urban nucleates.

- Tearing of the old compact fabric by erecting wide strait streets in between, caused a great damage to the old buildings within it.

- Bad paths and circulation network inside the old nucleate.

- Having new odd buildings within the old bazaar without considering the urban context of the old part of the city causes a visual pollution (fig. 11).

- Traffic jam in the center of the old city.

- Some of the most important old buildings can hardly find visitors like Qishla because of being bad-connected to the city and has a bad access (fig. 12).

- The lack of entertainment facilities.

- The lack and low level of public commercial and cultural-educational services, such as; restaurants, museums, hotels, etc.

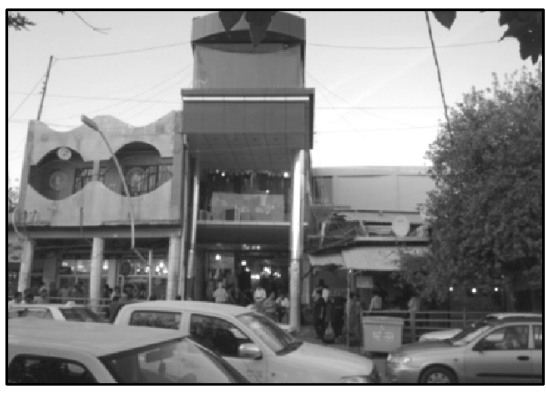

Figure 11: The absence of the urban context within the 1st urban nucleate [13].

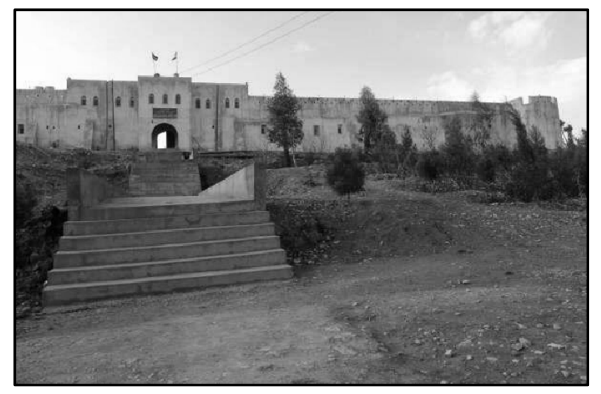

Figure 12: $\quad$ Bad access to the old Citadel of Qishla [12].

\subsection{Potentials}

- Most of Koya's old important buildings are in Baizagha and Qalat. That offers a high potentiality of connecting them with one project and treating them with a comprehensive plan that decides the level of conservation for each individually and as a whole (fig. 13). 
- Integrating old features with new ones in the same building, and/or integrating an old important building with new buildings, if treated in a good studied way could enhance the importance of that old building and its dominance over the urban context (fig. 14). Such treatment is recommended for the old buildings which set away from the old fabric like the old mill “Ashi Mam Khidir” (fig. 15).

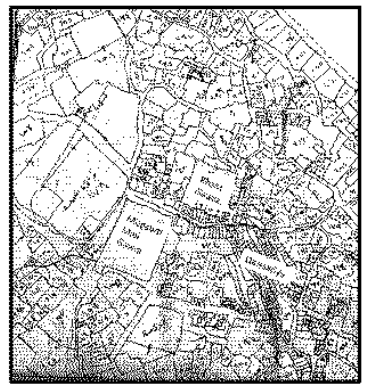

Figure 13: Old fabric and the location of some old buildings [10].

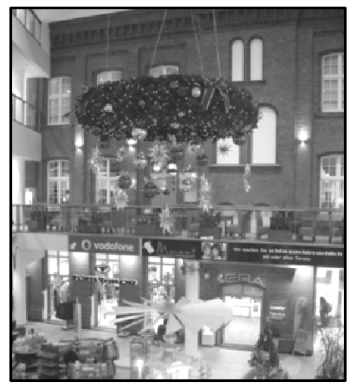

Figure 14: Old façade within the new building of Kofhof Gallery, Germany [14].

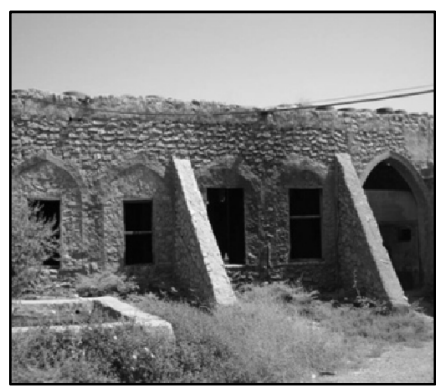

Figure 15: The old mill “Ashi Mam Khidir” [12]. 
- Emerging urban context to avoid visual pollution, by detecting common details that are shared in a group of buildings, or within an important one like Qishla and use them wisely in a rhythm in other buildings. (figs 16 and 17)

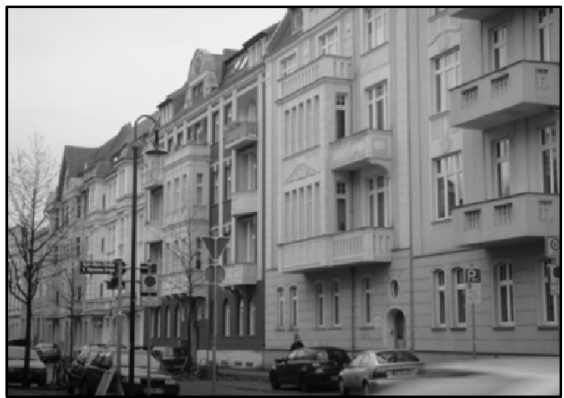

Figure 16: Urban context, Cottbus, Germany [14].

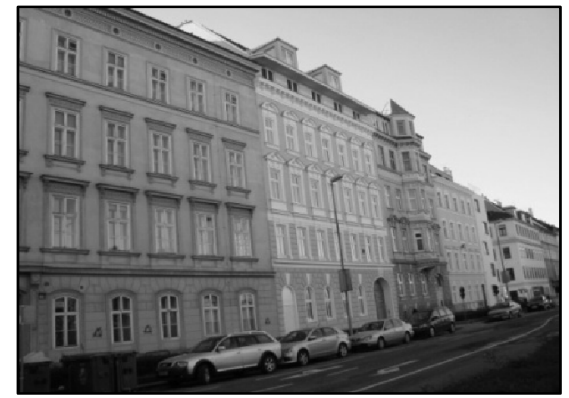

Figure 17: Urban context, Vienna, Austria [14].

- Supporting handcraftsmanship, cultural traditions, and letting local citizens participate in and be a part of the comprehensive plan is crucial to enhance tourism and provide good job opportunities (fig. 18).

- It's better if the new buildings could be out of the old city zone, but, if that's not possible, the new buildings should be built in a way that respects the old buildings besides them. Fig. 19 shows a new building with a glazed façade that reflects the image of an old building in front of it. Such treatment would suit the new building around Qishla, as the area around it is not welloccupied (fig. 20) and has a good potentiality to have a new project that enhance tourism and be a good access to the historic/cultural zones nearby (fig. 21).

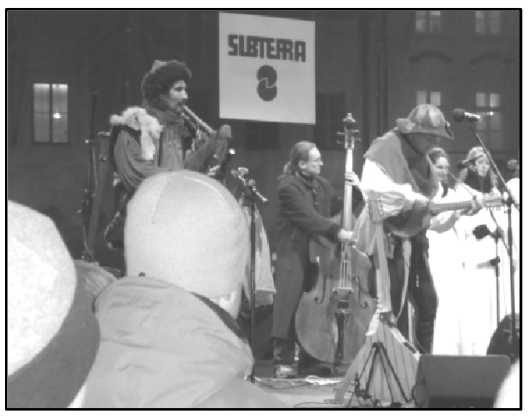

Figure 18: Local citizens’ participation, Praha, Czech [14].

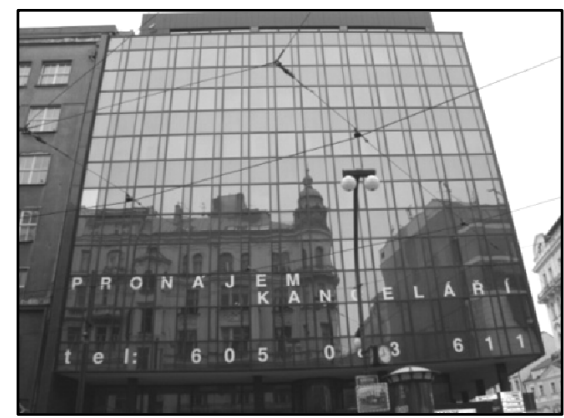

Figure 19: A new building that respects old heritage, Praha, Czech [14]. 


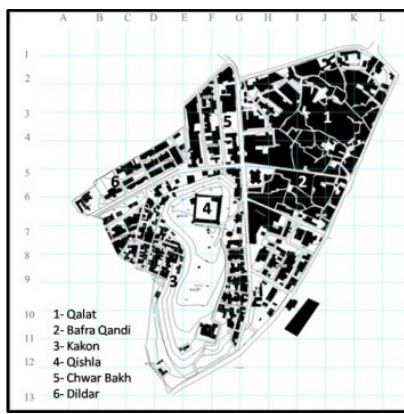

Figure 20: Urban fabric around Qishla (as built) [15].

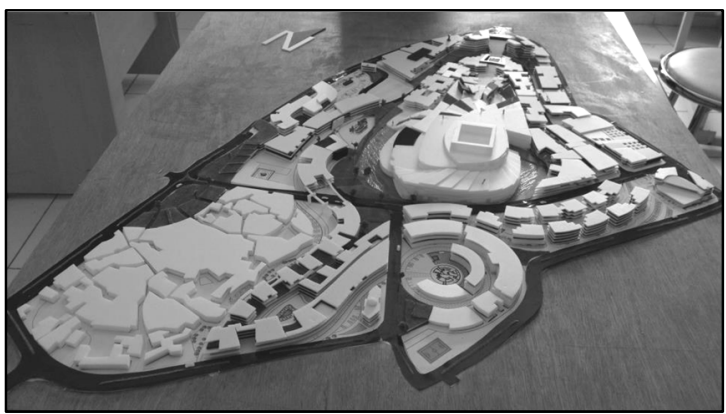

Figure 21: Urban fabric around Qishla (students’ proposal) [15].

\section{Conclusion}

Koya city is an ancient city in Kurdistan of Iraq that has a clear cultural, and political impact in the region. It should have a special care, as it has all what it takes to be a remarkable city and attracts tourism easily; but the challenges that face it aren't handled efficiently yet. The first step to deal with such challenges is to know the city through multi-disciplines studies in order to figure out its own identity that would be the main guide to decide the priorities in developing it. Considering the urban heritage as the most valuable fortune that could make such a positive change in city's situation, if and only if was treated properly. Treating heritage as individual pieces when having maintenance doesn't guarantee the efficient use of it, it's only when treating it as a whole urban network, giving it a comprehensive plan to decide the right way of conservation for each part regarding its relationship with the other parts according to the main concept and priorities of that comprehensive plan which should offers spaces for vital activities and encourage local citizens to be involved with this process.

\section{Recommendations}

- Having a comprehensive plan to deal with city's heritage which should consider a good scenario for circulation around and within historic/cultural buildings, focusing on important events in dramatic way to attract recipients.

- Rehabilitating old buildings by having new facilities and activities, and trying to link those buildings together with such activities that could also link the old with the new part of the city to revival the heritage and enhance tourism.

- Documenting heritage is the crucial step towards protecting and studying it. 
- Having strict rules from the municipality of Koya to keep a good urban context in the old part of the city; and declare them via a guide that should be publicized, so people would know the rules they should follow in that zone.

- Preventing the use of private cars in the old city and use traditional carthorses, and trams, etc. instead, to reduce air pollution and traffic jams.

- Fixing main streets, inner paths, and infrastructure.

- Any plan for maintaining or developing urban heritage should be approved and supervised by Experts' Committee, and be discussed publically in workshops and conferences.

- Citizens are the vital part of the comprehensive plan to revival city's culture.

\section{References}

[1] Erbil governorate formal website/Koya district; http:/hawlergov.org /ar/region.php?id=1330758754

[2] Faculty of Engineering, Koya city, published by Koya University, Shahab printing house, 2012, pp. 1-3.

[3] Ali, H., and Khalid, D., Morphology of Koya city (p.1), Kakon magazine, no. 16, August 2011, KRG, Iraq, pp. 39-40 (written in Kurdish).

[4] Website of Malpari Koya, (Kurdish website); http://www.koya.se/news /home/42-shwenawarykoya/624-qshlayekoya

[5] Website of Sotakhr magazine: a weekly political educational magazine, Erbil, KRG, Iraq; http://www.sotakhr.com/2006/index.php?id=10675

[6] Ali, H., and Khalid, D., Morphology of Koya city (p.2), Kakon magazine, no. 17, September 2011, KRG, Iraq, pp. 29-30 (written in Kurdish).

[7] Google maps, edited by the author.

[8] Qadifa, M. S., The image of Iraqi architecture before Islam, PhD dissertation, University of Baghdad, 2006.

[9] Al Qaisi, S. B. (the author), regarding the available information and the plan of Koya in 1992 from the municipality of Koya, 2013.

[10] The municipality of Koya, maps edited by the author.

[11] Bashdar, Q., personal photo, 2013.

[12] Faculty of Engineering archive, 2012.

[13] Bahzad, Z., personal photo, 2011.

[14] Al Qaisi, S. B. (the author), personal photo, 2009-2010.

[15] 4th year students, Architectural Eng. Dept., Koya University, 2013. 